\title{
Round four on the environment
}

\author{
Developing a culture of innovation is critical to a successful sustainable development strategy.
}

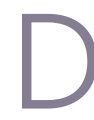
uring the 2012 United Nations conference on Sustainable Development, also known as $\mathrm{RIO}+20^{1}$, world leaders called for, among other things, a strengthened United Nations Environment Programme and as a result the United Nations Environment Assembly (UNEA) was created. As of today, $\mathrm{UNEA}^{2}$ is considered the world's highest-level decision-making body on environmental issues - it leads and enables intergovernmental action on the environment. Members of the Assembly meet every two years in Nairobi, Kenya, to advance global environmental policies and international environmental law. With the creation of UNEA, the environment acquired the same international status as issues such as peace, poverty, health and national security.

While this editorial is being written, government officials, non-governmental representatives and other key players are getting ready for the fourth session of the Environment Assembly (UNEA-4) to be held on 11-15 March. Three sessions took place before 2019, in June 2014, May 2016 and December 2017. Each meeting focused on a set of environmental issues: climate change vulnerability, impacts and adaptation at the first meeting; the health of environment and people at the second meeting; and how to achieve a pollution-free planet at the third. This year, the theme is 'Innovative solutions for environmental challenges and sustainable consumption and production, with particular attention to environmental problems related to poverty and natural resource management; life-cycle approaches to resource efficiency, energy, chemicals and waste management; and innovative sustainable business development at a time of rapid technological change ${ }^{3}$.

The official background information released ahead of the meeting suggests the Assembly will focus on how to develop a culture of innovation for sustainability with emphasis on the role of leadership and governance, education and finance and technology. UNEA-4 will also ensure that developing a culture of innovation builds on an inclusive and participatory approach to socio-economic development.

The scope of UNEA-4, as stated so far, looks promising. However, we should not lose sight of the fact that decision-makers

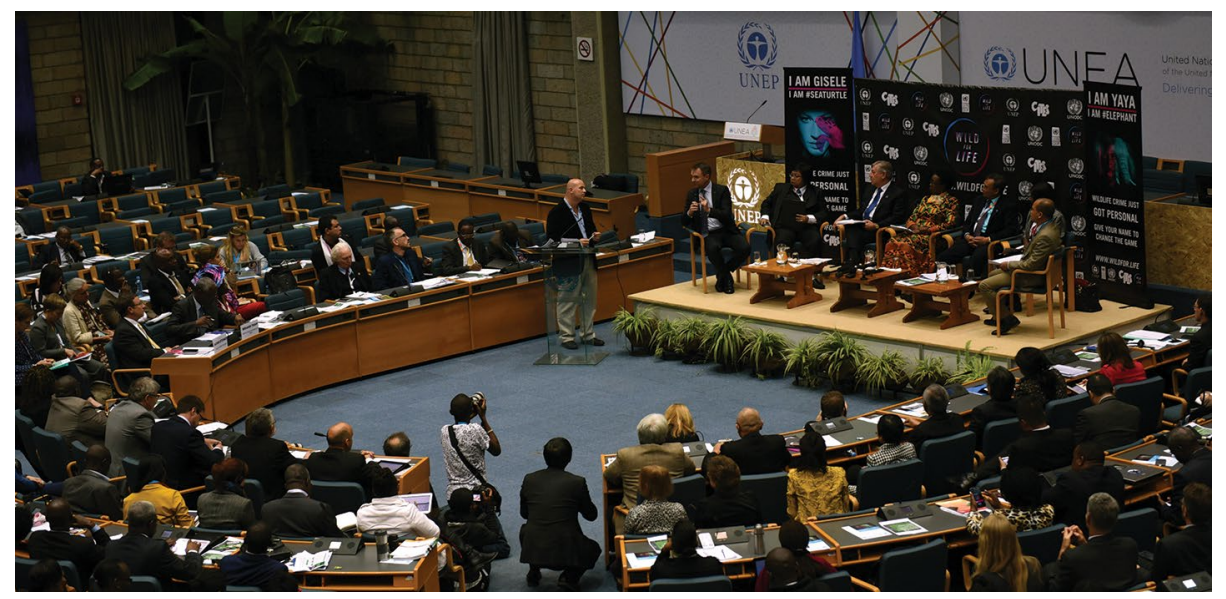

Credit: Xinhua / Alamy Stock Photo

supporting innovation for sustainable development need to draw on academic research to be effective. Likewise, scholars aiming at contributing to innovations must engage with relevant policy- and decisionmaking. Transdisciplinary research efforts here will do a lot to help bridge between academic and policy realms. But a much more difficult issue is identifying what is needed to actually innovate. UNEA mentions the role of leadership. What kind of leadership is needed to achieve sustainability? Here we should take a step back and reflect on what is meant by leadership. Quite often we refer to the role of charismatic figures who act to inspire and drive engagement. Although potentially useful for sustainability, that kind of leadership is far too limited in terms of driving actual change and innovation on the ground. We should look at leadership as the set of conditions that give to individuals the feeling of agency, the resources, the awareness, and the tools to act as enablers of a better world. In other words, we should embrace a notion of leadership that challenges how society and organizations currently work to practice and stimulate change ${ }^{4}$. Managers in organizations can be inspiring as well as catalysts for change; they can be strong action-oriented leaders. In order to trigger change, and develop and implement innovations for sustainability in their own organizations, managers have to appreciate what mediates understanding information on a problem. Each one of us interprets information such that our cultural predispositions and our values are reinforced. And this can create resistance to change, and so to innovation. Managers should embrace the divergence of views and interpretations and still build common goals ${ }^{5}$. Management theory can certainly shed light on the complex drivers and levers of change and how a culture of innovation for sustainability can be shaped within organizations. The innovation of the practices of organizations that on a daily basis manage and use natural resources, either directly or indirectly, is fundamental to achieve a more-sustainable development model. Of course, we need financial, legal, educational and technological innovations for sustainability as much as we need organizational ones. And we need all of them urgently. Participants at UNEA-4 have to ensure the works of the Assembly will lead to an innovative and actionable agenda for society and the environment.

Published online: 11 March 2019 https://oi.org/10.1038/s41893-019-0257-7

\footnotetext{
References

1. United Nations Conference on Sustainable Development, Rio+20 (United Nations, accessed 22 February 2019); https://sustainabledevelopment.un.org/rio20.htm

2. UN Environment Assembly and Governing Council (UN Environment, accessed 22 February 2019); https://go.nature com/2NwkrTr

3. Theme of the Fourth Session of the UN Environment Assembly (UN Environment, accessed 22 February 2019); https://go.nature.com/2Ex7CFO

4. Marshall, J., Coleman, G. \& Reason, P. Leadership for Sustainability: An Action Research Approach (Routledge, London, 2017).

5. Eztion, D. Nat. Sustain. 1, 744-749 (2018).
} 